\title{
Employment During Pregnancy Protects Against Postpartum Depression
}

\author{
Elisabet Vilella* et al. \\ Hospital Psiquiàtric Universitari Institut Pere Mata, IISPV, \\ Universitat Rovira i Virgili, Reus, \\ Spain
}

\section{Introduction}

Postpartum depression (PPD), a disorder that has severe consequences for mother and child (Pearlstein, Howard, Salisbury, \& Zlotnick, 2009), is the most common psychiatric disorder experienced by women after childbirth (McGarry, Kim, Sheng, Egger, \& Baksh, 2009), with a prevalence of $\sim 7 \%$ during the first three postpartum months (O'Hara, 2009). While different biological (Albacar et al., 2011; Brummelte \& Galea, 2010; Leung \& Kaplan, 2009) and genetic (Costas et al., 2010; Mahon et al., 2009; Sanjuan et al., 2008; Treloar, Martin, Bucholz, Madden, \& Heath, 1999) factors have been associated with PPD, most researchers have identified a history of affective disorder, depressive episodes and anxiety during pregnancy as the principal risk factors for PPD (O'Hara, 2009; Oppo et al., 2009). Social and psychological factors such as marital discord, low social support, stressful life events and lack of marital support have been strongly associated with PPD in several studies (Beck, 2001; Chen, 2001; O'Hara, 2009), and unemployment, which has been associated with depression in the general population (Stankunas, Kalediene, Starkuviene, \& Kapustinskiene, 2006), has been specifically associated with PPD (Chen, 2001; Inandi et al., 2002; Jardri et al., 2006; Lane et al., 1997; Miyake, Tanaka, Sasaki, \& Hirota, 2011; Posmontier, 2008; Rubertsson, Wickberg, Gustavsson, \& Radestad, 2005; Warner, Appleby, Whitton, \& Faragher, 1996). However, the results of studies on the impacts of other social variables such as income (Miyake et al., 2011) and the mother's level of education (Beck, 2001; Josefsson et al., 2002; Kozinszky et al., 2011; Miyake et al., 2011) are controversial. A recent study in Japan found that full-time employment and professional or technical employment significantly reduced the risk of PPD, leading researchers to claim that it is likely that a

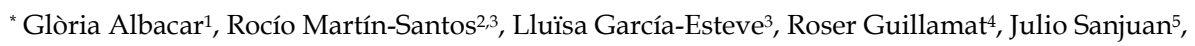
Francesca Cañellas', Isolde Gornemann ${ }^{7}$, Yolanda de Diego ${ }^{8}$, Ana Gaviria ${ }^{1}$ and Alfonso Gutiérrez-Zotes ${ }^{1}$ ${ }^{1}$ Hospital Psiquiàtric Universitari Institut Pere Mata, IISPV, Universitat Rovira i Virgili, Reus, Spain ${ }^{2}$ Neuropsychopharmacology Program, IMIM-Parc de Salut, Barcelona, Spain ${ }^{3}$ Department of Psychiatry, Institute of Neuroscience, Hospital Clínic, IDIBAPS, CIBERSAM, Barcelona, Spain ${ }^{4}$ Coorporació Sanitària Parc Tauli, Sabadell, Spain

${ }^{5}$ Faculty of Medicine, CIBERSAM, Universitat de Valencia, Valencia, Spain

${ }^{6}$ Hospital Universitari Son Dureta, UNICS, Palma de Mallorca, Spain

'Fundación para la e-Salud, Málaga, Spain

${ }^{8}$ Hospital Carlos Haya, Málaga, Spain
} 
higher degree of job satisfaction protects one from PPD (Miyake et al., 2011). Furthermore, unemployment, and the attendant lack of income, during the postpartum period has been associated with lower levels of self-esteem and negative self-perception, both of which are risk factors for PPD (Chen, 2001). Absences due to sickness are more frequent in pregnant women than in non-pregnant women (A. Sydsjo, Sydsjo, \& Alexanderson, 2001), and sick leave is a strong risk factor for the presence of postpartum depressive symptoms (Josefsson et al., 2002).

Neuroticism a fundamental personality trait which has also been implicated in postpartum depression (Beck, 2001), correlates with a negative perception of one's social and economic statuses and tends to intensify feelings and beliefs about illness (Alfonsi, Conway, \& Pushkar, 2011). To our knowledge, no studies have assessed the relationship among employment, sick leave, personality traits and PPD. In a previous study on biological markers for PPD, we identified an association between employment, neuroticism and PPD (Albacar et al., 2011). We hypothesized that women with higher scores for neuroticism would be more frequently unemployed or on sick leave during pregnancy and, therefore, be more at risk for PPD. Conversely, we hypothesized that women who are more active during pregnancy would be less susceptible to PPD.

\section{Materials and methods}

\subsection{Study population}

Our study population was obtained from a larger multicenter prospective study of 1,804 women recruited in Spain between December 2003 and October 2004 to study genetic and environmental factors associated with PPD (Sanjuan et al., 2008). All participants volunteered, were of Spanish origin (Caucasian), were over 18 years of age and had a singleton baby. Participants with depression or other psychiatric illnesses during pregnancy were excluded from the study. Other exclusion criteria included cognitive impairments, the presence of a medical illness that prevented participation and the lack of data for any of the considered variables. Overall, 1,724 women were included in the study. The ethics committees at each of the participating hospitals approved the study.

\subsection{Procedures}

Participants were contacted $48 \mathrm{~h}$ postpartum at the hospital obstetric unit and invited to participate by the research team, which was comprised of clinical psychologists and psychiatrists. Upon acceptance, participants completed semi-structured interviews for the collection of socio-demographic data. Obstetric data were collected from obstetric medical records.

Socio-demographic variables included age (years), marital status (grouped as with or without partner), educational level (grouped as primary school equivalent to 9 years of education, secondary school equivalent to 13 years of education or college degree equivalent to 20 years of education), occupational status before and during pregnancy (grouped as active, e.g., employed, housewife and student, or inactive, e.g., unemployed and sick leave), type of coexistence (grouped as parents, own family or other) and perceived household income (grouped as adequate, low or very low). 
Obstetric variables of interest included the presence of a medical illness, defined as the presence of any medical condition that involved either hospitalization or pharmacological treatment during pregnancy or the peripartum period. This variable was dichotomized as presence or absence.

Depressive symptoms were screened 8 weeks and 32 weeks postpartum using the validated Spanish language version of the Edinburgh Postnatal Depression Scale (EPDS) (Garcia-Esteve, Ascaso, Ojuel, \& Navarro, 2003). Participants were screened at 8 weeks to accommodate mothers scheduled for a postpartum obstetric visit at this time, and most bibliographic references, including the Diagnostic and Statistical Manual of Mental Disorders IV (DSM IV), state that postpartum depression usually develops during the first 4 weeks postpartum. Depression was assessed at 32 weeks on the basis of data stating that postpartum depression can develop up to 12 months postpartum (O'Hara, 2009). A baseline assessment was conducted $48 \mathrm{~h}$ postpartum when the mother was still in the hospital.

Women who scored higher than 9 on the EPDS at 8 or 32 weeks postpartum were identified as probable depression cases and were further evaluated using the Spanish language version of the Diagnostic Interview for Genetics Studies (DIGS) (Roca et al., 2007), which was adapted (Sanjuan et al., 2008) to assess the DSM IV criteria for PPD and thereby confirm the diagnosis.

To assess personality traits, the Spanish validated version of the Eysenck Personality Questionnaire-R short scale (EPQ-RS) (Ortet G, 1997) was used. The EPQ-RS consists of 48 items taken from the 100-item EPQ-R and measures the following dimensions of personality: extraversion, neuroticism and psychoticism. We obtained t-scores for the population according to gender and age.

\subsection{Statistical analysis}

Qualitative variables were presented as percentages, and quantitative variables, including maternal age and dimensional personality traits, were presented as means and standard deviations (SD). A chi-square test was used to compare the distribution of categorical qualitative variables across PPD and non-PPD subgroups with the critical value of the residuals of the contingency tables to determine if the observed frequency in a category was higher or lower than expected. The same procedure was used to compare different social variables among occupational status categories. Student's t-test was used to analyze continuous predictor variables, and the McNemar Bowker test was used to compare the frequencies of paired data that indicated differences in occupation status before and during pregnancy. A logistic regression was used to measure the relationship between each of the selected variables (age, marital status, type of coexistence, medical illness, education level, perceived household income and personality traits) and employment status (active versus inactive and sick leave versus other). After identifying occupational status risk factors, we applied a logistic regression to assess a possible association between occupational status during pregnancy and PPD. Marital status, medical illness during pregnancy and maternal personality traits, including neuroticism, psychoticism and extraversion, were included as covariables. Perceived household income was excluded from the logistic regression model because of its colinearity with occupational 
status during pregnancy, that is, unemployed women had a higher perception of low household income. Education level, although highly associated with occupational status, did not add any significance in the regression models and was therefore excluded in the final analysis. Two multivariate regression models were developed to check our two hypotheses. The first model was applied to assess a possible relationship between sick leave during pregnancy and PPD. The second model was used to assess a possible protective effect of being active, as opposed to being inactive, on PPD. All two-tailed pvalues $<0.05$ were considered to be statistically significant. We used SPSS version 15.0 for all statistical analyses.

\section{Results}

\subsection{Socio-demographics, obstetric characteristics and personality traits}

Of the 1,724 women sampled, 163 (9.5\%) were clinically diagnosed as depressed. The sociodemographic, obstetric and maternal personality characteristics are shown in Table 1. Women in the PPD group more frequently lived without a partner (PPD 6.7\% versus nonPPD 3.1\%; p-value = 0.02), experienced a medical illness during pregnancy (PPD 25.2\% versus non-PPD 19.5\%; p-value $=0.004$ ) and considered their household income to be low $(\mathrm{PPD} 46.0 \%$ versus non-PPD 35.2\%; $\mathrm{p}$-value $=0.001)$ or very low $(\mathrm{PPD} 3.1 \%$ versus $0.8 \%$; $\mathrm{p}$ value $=0.001)$. Mothers in the PPD group also recorded higher mean scores for neuroticism $(47.2 \pm 10.4$ versus $40.2 \pm 8.2$; $\mathrm{p}$-value $=0.001)$ and psychoticism $(47.8 \pm 9.1$ versus $46.1 \pm 8.6$; $\mathrm{p}$ value $=0.01$ ) than mothers in the non-PPD group. Conversely, women with PPD had lower mean extraversion scores than women in the non-PPD group ( $49.0 \pm 10.3$ versus $51.4 \pm 9.6$; $\mathrm{p}$ value $=0.001)$.

\subsection{Occupation status before and during pregnancy}

Figure 1 shows the occupational status before and during pregnancy. Before pregnancy, only $5 \%$ of women were inactive, but during pregnancy, this value increased to $23 \%$ (Figure 1 panel A). Of those categorized as inactive, $4.4 \%$ were unemployed and $0.6 \%$ were on sick leave before pregnancy; during pregnancy, $12.2 \%$ were unemployed and $10.9 \%$ were on sick leave (Figure 1 panel B).

\subsection{Risk factors for occupation status}

Prior to the main analysis, we assessed associations between the socio-demographic, obstetric and personality trait variables and occupation status. Using a binary logistic regression, we explored the association of these variables with being active and being on sick leave (Table 2). Being active was positively associated with a higher level of education ( $p$-value $<0.001$ for secondary school, and $p$-value $<0.001$ for a college degree). We further determined that higher scores for neuroticism and psychoticism were negatively associated with being active ( $\mathrm{p}$-value $=0.02$ and $\mathrm{p}$-value $=0.01$, respectively). Sick leave was associated with a younger age $(p$-values $=0.004)$, the presence of a medical illness $(p$-value $=0.001)$ and lower levels of education ( $p$-value $<0.019$ for secondary school and $p$-value $=0.003$ for primary school). While living with parents appeared to protect against sick leave, the result was not statistically significant $(p$-value $=0.06)$. 


\begin{tabular}{|c|c|c|c|c|}
\hline Variables & $\begin{array}{c}\text { Total } \\
\text { sample }\end{array}$ & PPD & Non-PPD & $\mathbf{P}$ \\
\hline Participants (N) & 1724 & 163 & 1561 & \\
\hline Age (years) $)^{a}$ & $31.8 \pm 4.6$ & $31.7 \pm 5.0$ & $31.8 \pm 4.6$ & 0.85 \\
\hline \multicolumn{5}{|c|}{ Living with partner $(\%)^{b}$} \\
\hline Yes & 96.6 & 93.3 & 96.9 & \multirow{2}{*}{0.02} \\
\hline No & 3.4 & 6.7 & 3.1 & \\
\hline \multicolumn{5}{|c|}{ Type of coexistence $(\%)$} \\
\hline Parents & 3.6 & 3.1 & 3.7 & \multirow{3}{*}{0.72} \\
\hline Own family & 94.7 & 94.5 & 94.7 & \\
\hline Other & 1.7 & 2.5 & 1.7 & \\
\hline \multicolumn{5}{|l|}{ Medical illnessc } \\
\hline Yes & 16.8 & 25.2 & 15.9 & \multirow{2}{*}{0.004} \\
\hline No & 83.2 & 74.8 & 84.1 & \\
\hline \multicolumn{5}{|c|}{ Education level (\%) } \\
\hline Primary school & 30.5 & 33.7 & 30.2 & \multirow{3}{*}{0.42} \\
\hline Secondary school & 41.4 & 42.3 & 41.3 & \\
\hline College degree & 28.1 & 23.9 & 28.5 & \\
\hline \multicolumn{5}{|c|}{ Perceived household income $(\%)$} \\
\hline Adequate & 62.8 & 50.9 & 64.1 & \multirow{3}{*}{$<0.001$} \\
\hline Low & 36.2 & 46.0 & 35.2 & \\
\hline Very low & 1.0 & 3.1 & 0.8 & \\
\hline \multicolumn{5}{|l|}{ Personality traits ${ }^{a}$} \\
\hline Extraversion & $51.2 \pm 9.1$ & $49.0 \pm 10.3$ & $51.4 \pm 9.0$ & 0.001 \\
\hline Neuroticism & $40.9 \pm 8.6$ & $47.2 \pm 10.4$ & $40.24 \pm 8.2$ & 0.0001 \\
\hline Psychoticism & $46.2 \pm 8.6$ & $47.8 \pm 9.1$ & $46.1 \pm 8.6$ & 0.01 \\
\hline
\end{tabular}

aValues are given as mean $\pm \mathrm{SD}$ and compared to student's t-test

bValues are given as percentages and compared by chi-square test

cIncludes any medical condition that involved either hospitalization or pharmacological treatment during pregnancy and immediately before, during or after delivery

Table 1. Socio-demographic, obstetric and personality trait variables for all participants and for the PPD and non-PPD groups.

\subsection{Occupational status and PPD}

Figure 2 shows the percentages of active and inactive women before and during pregnancy. The percentages of active (95\%) and inactive (5\%) women before pregnancy were similar in the group of women who developed PPD compared with the group that did not develop PPD (Figure 2 panel A). During pregnancy, however, the percentage of inactive women increased from 5\% to $22 \%$ in the group that did not develop PPD and from 5\% to $36 \%$ in the 


\begin{tabular}{|c|c|c|c|c|c|c|}
\hline \multirow[b]{2}{*}{ Variables } & \multicolumn{3}{|c|}{ Active vs. Inactive ${ }^{a}$} & \multicolumn{3}{|c|}{ Sick leave vs. Active } \\
\hline & $\mathrm{OR}^{\mathrm{b}}$ & CI & $\mathbf{P}$ & OR & CI & $\mathbf{P}$ \\
\hline Age & 0.98 & $0.96-1.01$ & 0.30 & 1.05 & $1.01-1.08$ & 0.004 \\
\hline \multicolumn{7}{|c|}{ Living with partner (\%) } \\
\hline Yes & 1.00 & & & 1.00 & & \\
\hline No & 0.67 & $0.33-1.33$ & 0.25 & 0.42 & $0.13-1.37$ & 0.15 \\
\hline \multicolumn{7}{|c|}{ Type of coexistence (\%) } \\
\hline Own family & 1.00 & & & 1.00 & & \\
\hline Parents & 0.55 & $0.27-1.13$ & 0.10 & 0.25 & $0.06-1.05$ & 0.06 \\
\hline Other & 0.81 & $0.33-2.01$ & 0.65 & 0.28 & $0.03-2.09$ & 0.21 \\
\hline \multicolumn{7}{|l|}{ Medical ilnesss ${ }^{c}$} \\
\hline No & 1.00 & & & 1.00 & & \\
\hline Yes & 1.23 & $0.92-1.64$ & 0.15 & 1.79 & $1.25-2.56$ & 0.001 \\
\hline \multicolumn{7}{|c|}{ Education level (\%) } \\
\hline College degree & 1.00 & & & 1.00 & & \\
\hline Secondary school & 1.75 & $1.28-2.38$ & $<0.001$ & 1.61 & $1.08-2.41$ & 0.019 \\
\hline Primary school & 2.70 & $1.97-3.69$ & $<0.001$ & 1.91 & $1.25-2.91$ & 0.003 \\
\hline \multicolumn{7}{|c|}{ Perceived household income (\%) } \\
\hline Adequate & 1.00 & & & 1.00 & & \\
\hline Low & 1.28 & $1.02-1.62$ & 0.03 & 1.02 & $0.74-1.41$ & 0.86 \\
\hline Very low & 1.12 & $0.36-3.49$ & 0.83 & 0.54 & $0.07-4.20$ & 0.56 \\
\hline \multicolumn{7}{|l|}{ Personality traits } \\
\hline Extraversion & 1.00 & $0.99-1.02$ & 0.21 & 1.00 & $0.98-1.02$ & 0.45 \\
\hline Neuroticism & 1.01 & $1.00-1.02$ & 0.02 & 1.01 & $0.99-1.03$ & 0.17 \\
\hline Psychoticism & 1.02 & $1.00-1.03$ & 0.01 & 1.01 & $0.99-1.03$ & 0.15 \\
\hline
\end{tabular}

aActive defined as employed, housewife or student and inactive as unemployed and on sick leave bBinary logistic regression Includes any medical condition that involved either hospitalization or pharmacological treatment during pregnancy and immediately before, during or after delivery

Table 2. Odds ratios (ORs) and 95\% confidence intervals (CIs) for occupational status in relation to selected socioeconomic, obstetric and personality trait variables for 1,724 Spanish participants.

group that did. The increase in inactivity status during pregnancy was due to an increase in unemployment, from $4.5 \%$ to $11.9 \%$ in the non-PPD group and from $4.3 \%$ to $15.3 \%$ in the PPD group, and an increase in sick leave, from $0.6 \%$ to $9.9 \%$ in the non-PPD group and from $0.6 \%$ to $20.9 \%$ in the PPD group. Inactivity before pregnancy was not associated with PPD (data not shown); however, inactivity during pregnancy was statistically different in the PPD group compared with the non-PPD group (Figure 3 ). 
A
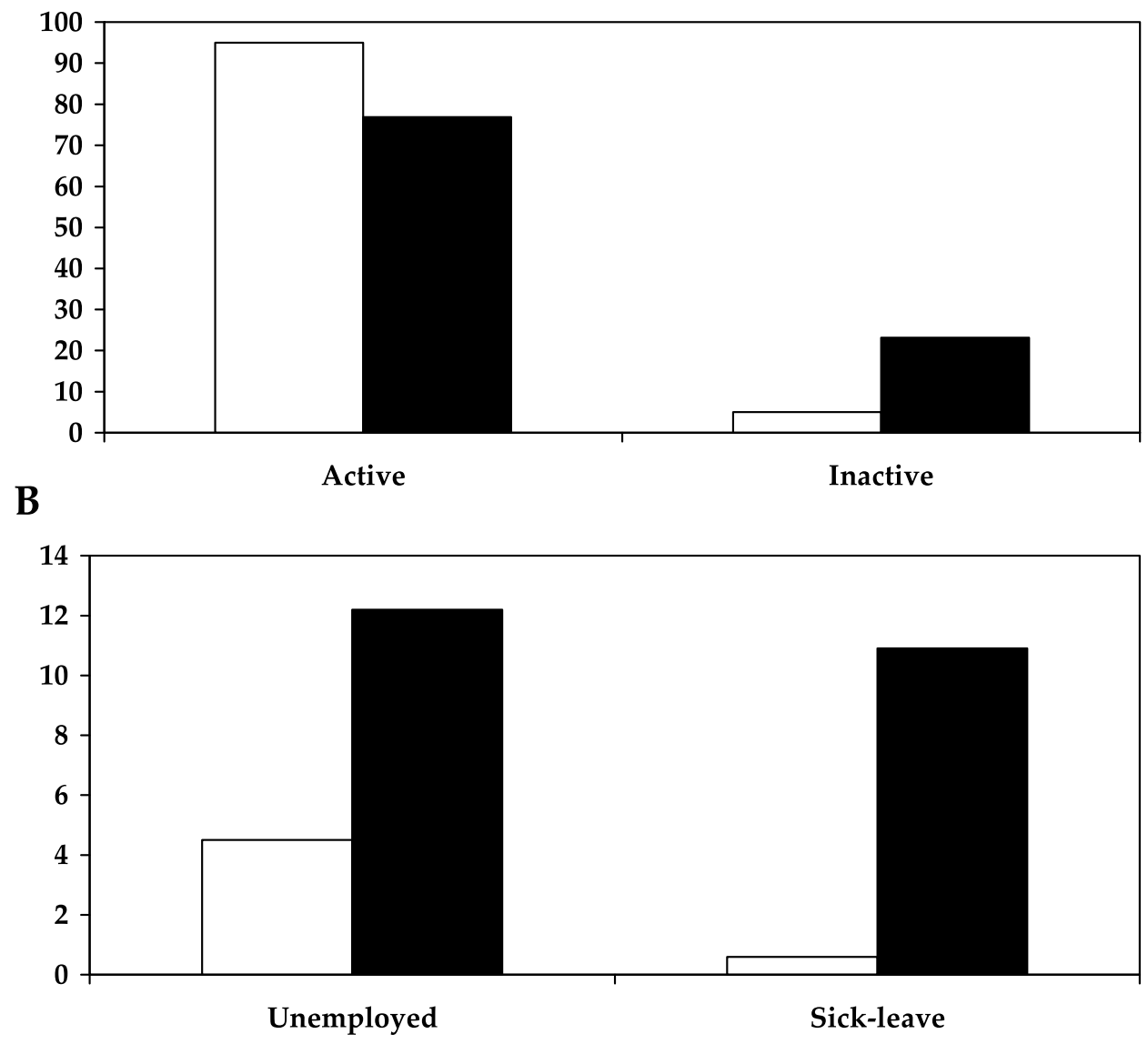

$\square$ Before $\square$ During

Fig. 1. Occupation status before and during pregnancy.

Panel A shows the distribution of women according to their occupation status of active (employed, student or housewife) or inactive (unemployed or on sick leave). Panel B shows the distribution of inactive women according to their status of unemployed or on sick leave. Open bars represent values before pregnancy, and filled bars represent values during pregnancy. MacNemar Bowker test p-value $<0.001$. 
A

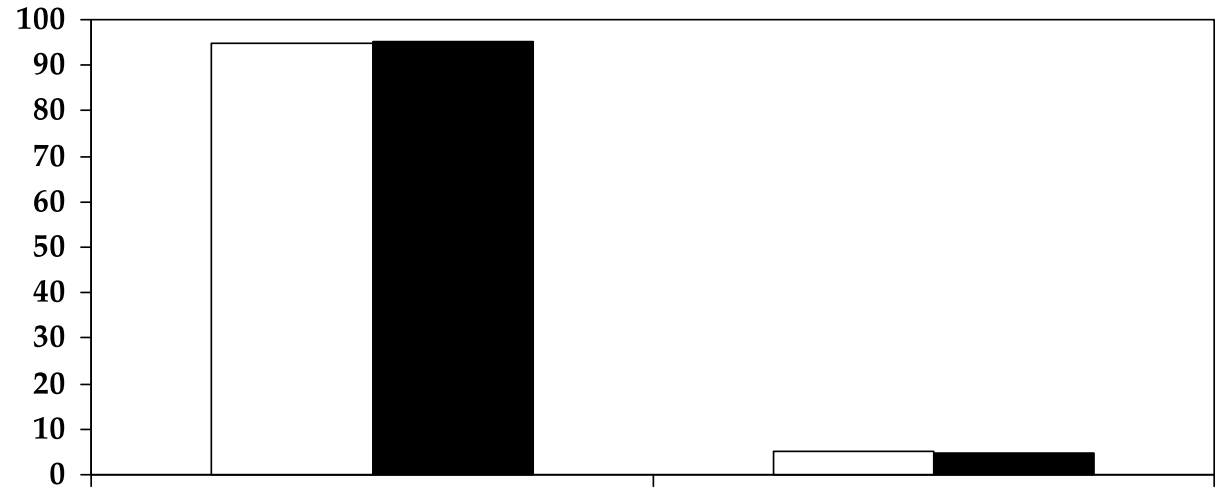

B

Active

Inactive

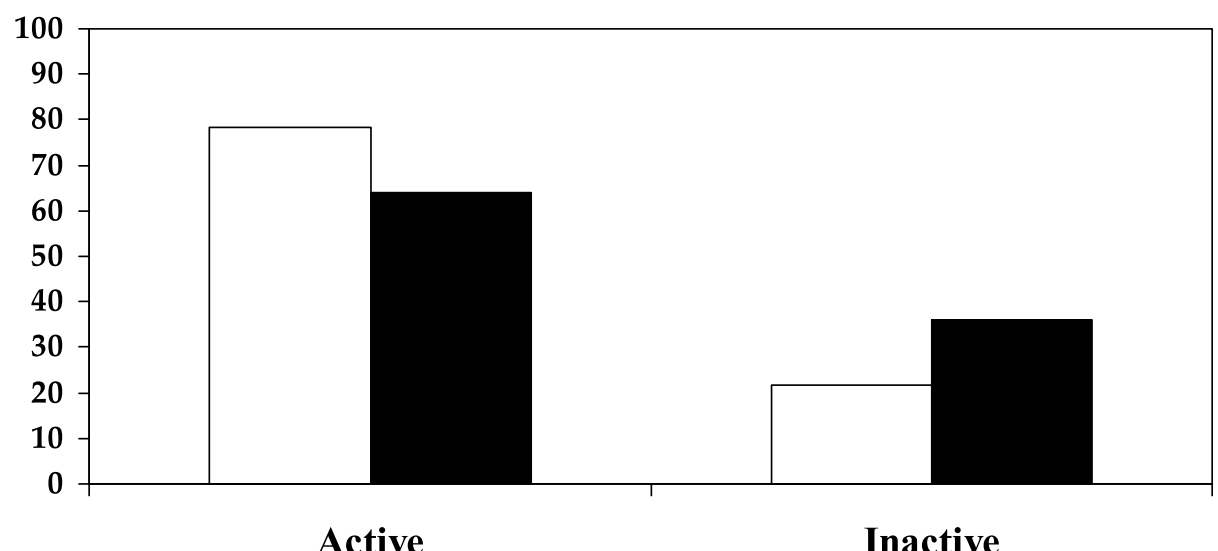

$\square$ Non-PPD $\square$ PPD

Fig. 2. Occupation status before and during pregnancy and PPD.

Panel A shows the distribution of active and inactive women before pregnancy according to the diagnosed presence or absence of PPD. Panel B shows the distribution of active and inactive women during pregnancy according to their PPD diagnosis. Open bars represent women who did not develop PPD, and filled bars represent women who did develop PPD. MacNemar Bowker test $\mathrm{p}=$ value $<0.001$. 


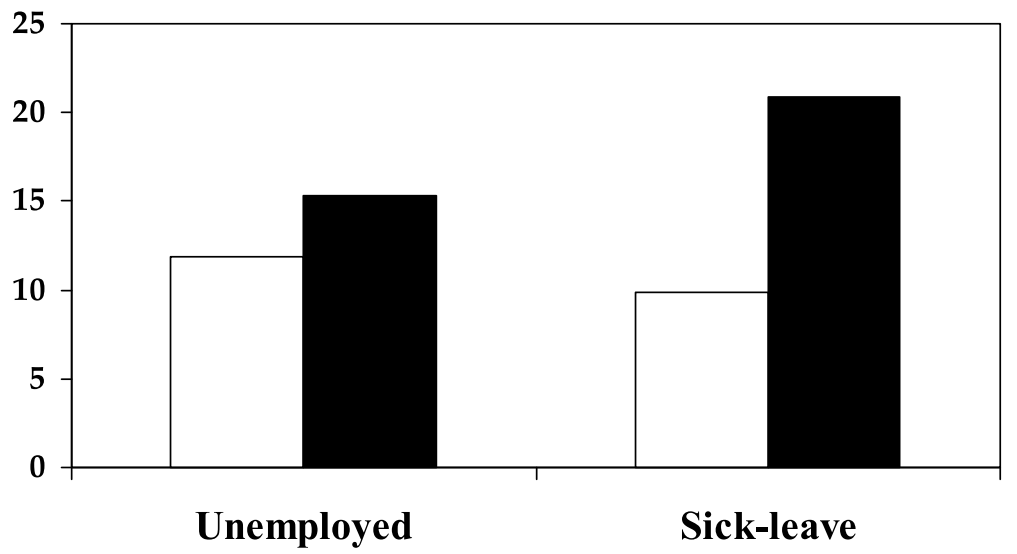

$\square$ Non-PPD $\square$ PPD

Fig. 3. Inactivity during pregnancy and PPD.

The distribution of women categorized as inactive (unemployed or on sick leave) during pregnancy, according to their subsequent PPD diagnoses. Open bars represent women who did not develop PPD, and filled bars represent women who did develop PPD. ANOVA p-value $<0.001$.

Finally, using a multivariate logistic regression analysis, we explored the relationship between occupation status and PPD, considering personality traits as covariables. The sociodemographic and obstetric variables explored in the binary logistic regression were included as covariables. Two models were constructed; one explored the risk that being on sick leave will lead to PPD, and the other explored the way in which being active protects against PPD. These results are shown in Table 3.

In summary, being on sick leave, not having a partner, having a medical illness and demonstrating a likelihood for neuroticism are all indicators of risk for PPD. The multivariate model explains $13 \%$ of the PPD variance (Nagelkerke $\mathrm{R}^{2}=0.135$ ). While the variable "being on sick leave" is an independent risk factor for PPD, its strong correlation with the variable "presence of medical illness" is noteworthy. Being active, having a partner and not having a medical illness appear to prevent the development of PPD. The model also explains $13 \%$ of the PPD variance. 


\begin{tabular}{|c|c|c|c|c|c|}
\hline $\begin{array}{l}\text { Regression } \\
\text { model }\end{array}$ & $\begin{array}{l}\text { Variables in the } \\
\text { equation }\end{array}$ & $\begin{array}{c}\text { Wald } \\
\text { statistic }\end{array}$ & $\beta$ & OR $(95 \%$ CI $)$ & $\mathbf{P}$ \\
\hline \multicolumn{6}{|c|}{ Model 1. Sick-leave risk to PPDa } \\
\hline & vithout partner & 6.36 & 0.94 & $2.56(1.23-5.34)$ & 0.012 \\
\hline & e of medical illness & 4.36 & 0.43 & $1.54(1.02-2.31)$ & 0.037 \\
\hline & sick leave & 19.09 & 0.98 & $2.68(1.72-4.18)$ & 0.0001 \\
\hline & oyed & 2.56 & 0.397 & $1.48(0.91-2.41)$ & 0.109 \\
\hline & rsion & 2.60 & -0.014 & $0.98(0.98-1.00)$ & 0.10 \\
\hline & cism & 63.57 & 0.075 & $1.07(1.05-1.09)$ & 0.0001 \\
\hline & icism & 0.072 & -0.003 & $0.99(0.97-1.01)$ & 0.78 \\
\hline
\end{tabular}

Model 2. Being active protection to $\mathrm{PPD}^{\mathrm{b}}$

\begin{tabular}{lcccc} 
Living with partner & 6.0 & -0.91 & $0.40(0.19-0.83)$ & 0.014 \\
Absence of medical illness & 5.1 & -0.46 & $0.62(0.42-0.94)$ & 0.024 \\
Active occupational status & 14.7 & -0.70 & $0.50(0.35-0.70)$ & $<0.001$ \\
Extraversion & 2.5 & -0.014 & $0.99(0.97-1.00)$ & 0.11 \\
Neuroticism & 62.2 & 0.074 & $1.07(1.05-1.09)$ & $<0.001$ \\
Psychoticism & 0.09 & -0.003 & $0.99(0.98-1.01)$ & 0.75 \\
\hline
\end{tabular}

aThe "enter" method was used. Hosmer-Lemeshow $P=0.81$. Nagelkerke $R^{2}=0.13$

bThe "enter" method was used. Hosmer-Lemeshow $\mathrm{P}=0.55$. Nagelkerke $\mathrm{R}^{2}=0.13$

Table 3. Multivariate logistic regression analysis to assess the relationship between occupational status and PPD.

\section{Discussion}

PPD was identified in $9.5 \%$ of subjects, in agreement with PPD prevalences in other studies (O'Hara, 2009). The percentage of women categorized as inactive before pregnancy was $4.5 \%$ lower than the official percentage of unemployment during the period of our study in Spain (2003-2004; National Institute of Statistics) in an age- and gender-match comparison. Note that data from the National Institute of Statistics refers exclusively to employment, and we included in the activity group employed women but also students and housewife activity. Surprisingly, the percentage of inactive women increased to $23 \%$ during pregnancy. An important cause for this dramatic change was the increase in sick leave, which increased 18 times over the normal rate of women on sick leave. However, research has indicated that sick-leave frequency increases during pregnancy (Josefsson et al., 2002; A. Sydsjo et al., 2001). Interestingly, unemployment during pregnancy in our sample almost tripled. Because we excluded women with depression during pregnancy, this increase in sick leave was not likely caused by depression, as other authors have reported (Bermejo et al., 2010). As we did not collect evidence regarding the cause of this increase, we do not know if pregnant women decided not to work or if their unemployment was due to employee discrimination. The strong association among a low level of education, sick leave and unemployment suggest that 
women with lower levels of education have discontinuous jobs that, perhaps by one's own decision, are not renewed following pregnancy.

On the basis of previous reports (Akman, Uguz, \& Kaya, 2007; Beck, 2001), we hypothesized that neuroticism would strongly influence occupation status and, consequently, the development of PPD. Our binary logistic regression results show that neuroticism and psychoticism were significantly associated with an inactive occupation status, albeit with a very low $\mathrm{OR}(\mathrm{OR}=1.01$ and 1.02, respectively). Because the inactive category included unemployment and sick leave, we explored the association of neuroticism with unemployment and sick leave separately and identified an association with unemployment but not with sick leave. Pregnant women with higher neuroticism scores are potentially more likely to be unemployed because of their perception of poor personal health (Alfonsi et al., 2011). Surprisingly, however, a significant number of women with high psychoticism scores were unemployed. This could be because women with higher psychoticism scores have significant social disabilities and are thus unable to find jobs. A higher level of education was associated with a better occupation status, possibly because a better education makes finding a job easier.

The most important finding is that being on sick leave tripled the risk for PPD. This risk was heightened for those living without a partner, having higher scores for neuroticism and having a medical illness during pregnancy. Neuroticism and the presence of a medical illness are independent risk factors for PPD; thus, their statistical significance in the model was maintained in the multivariate analysis. We also found that being active reduced the risk of PPD by one-half. This protection from PPD increased when a woman was living with a partner, had no medical illness during pregnancy and had lower neuroticism scores. Our model of risk variables for the link between occupation status and PPD is summarized in Figure 4. Previous studies have reported an association between maternal neuroticism and PPD (Jones et al., 2010) while others have studied the association between socioeconomic factors and PPD (Akincigil, Munch, \& Niemczyk, 2010). However, no studies have examined the relationship among a mother's personality traits, socioeconomic variables and PPD.

Sickness is associated with a compromised level of health in non-pregnant women (Bermejo et al., 2010), and the accompanying lowered self-perception often results in a decreased level of physical activity. The main reason for sick leave during pregnancy is back pain (G. Sydsjo \& Sydsjo, 2005). Previous reports have indicated that physical activity during pregnancy plays an important role in minimizing the risk of PPD (Ersek \& Brunner Huber, 2009). Sick leave may be associated with adverse social and economic consequences, both of which have been implicated in PPD (Boyd, Mogul, Newman, \& Coyne, 2011). Our results are consistent with previous studies that show employment, especially full-time, and a professional or technical job during pregnancy may reduce the risk of PPD (Inandi et al., 2002; Jardri et al., 2006; Lane et al., 1997; Miyake et al., 2011; Rubertsson et al., 2005; Warner et al., 1996). However, some researchers did not find an association between employment and PPD (Akman et al., 2007; Ekuklu, Tokuc, Eskiocak, Berberoglu, \& Saltik, 2004; Goyal, Gay, \& Lee, 2010; Rich-Edwards et al., 2006; Tannous, Gigante, Fuchs, \& Busnello, 2008; Weiss, Sheehan, \& Gushwa, 2009). This controversy can be partially explained by several methodological differences in the studies. 


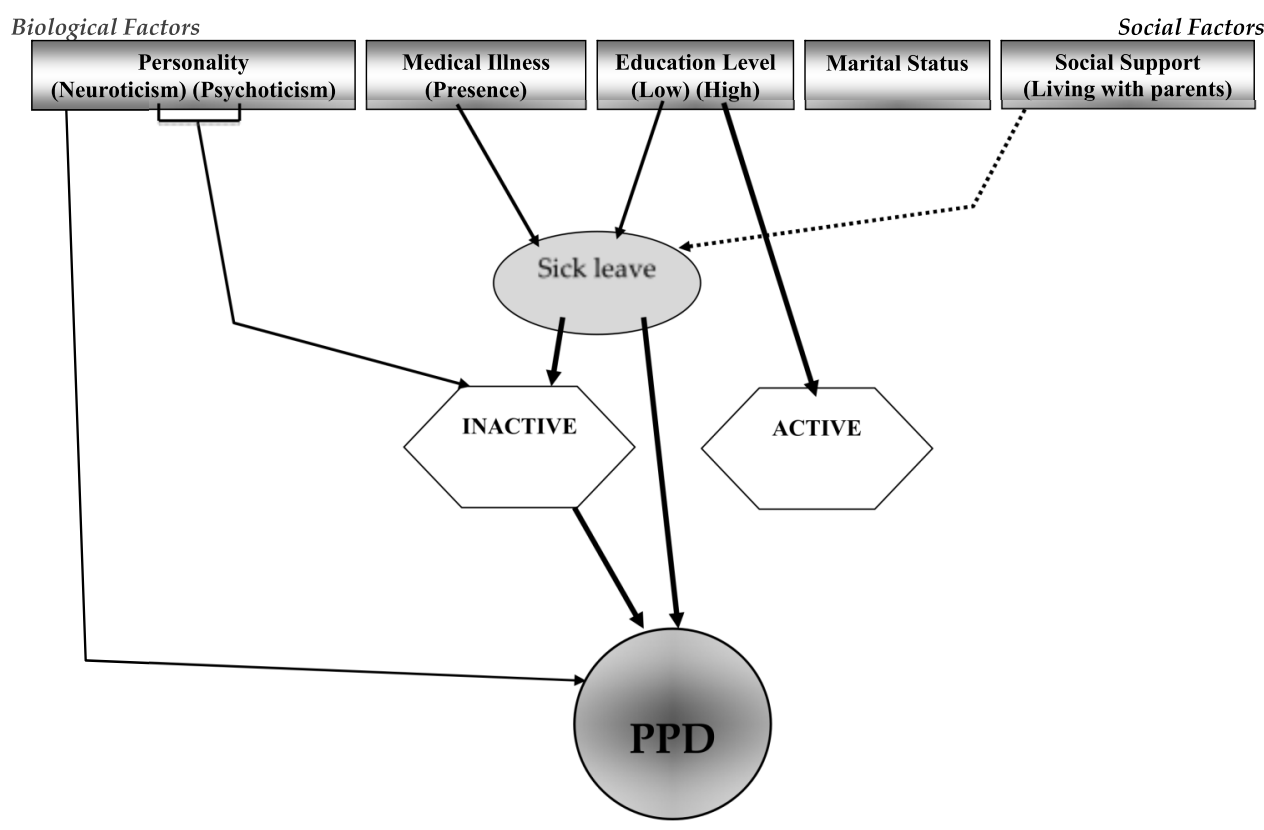

Fig. 4. The direct or indirect relationship between selected variables and PPD.

Thickness of lines is proportional to $\mathrm{p}$-value. Discontinuous lines represent a non-significant association $(\mathrm{p}$-value $=0.06)$.

Our study had several methodological strengths. The sample size of 1,724 is large, and the sample group was composed exclusively of Spanish Caucasian women. The presence of a psychiatric illness during pregnancy was an exclusion criteria; thus, biases due to psychiatric conditions were avoided. Although previous studies have assessed employment during pregnancy and PPD, to our knowledge, this is the first study to assess the association of criteria other than employment status with PPD. Moreover, we used a psychiatric diagnostic of PPD based on the DSM IV that considers a broad period of occurrence. Most studies have been based only on the presence of depressive symptoms. Finally, our study explored the relationship between occupation and PPD while also considering individual neuroticism scores.

However, our study also has limitations. Some interesting variables such as the cause of sick leave, the level of marital quality support, an accurate diagnostic of illness during pregnancy and job type were not registered because this study was initially designed to explore a genetic-environment vulnerability to PPD (Sanjuan et al., 2008). Despite its limitations and the need for future investigations, interesting insights can be drawn from this work. First, sick leave may not produce the intended benefits expected by pregnant women. Pregnancy is associated with asthenia, back pain and insomnia. As a result, family doctors and obstetricians often grant sick leave without a clear medical cause to avoid conflicts (Larsson, Sydsjo, Alexanderson, \& Sydsjo, 2006). Perhaps a more reflexive attitude is to implement psycho-educational interventions for pregnant women in an attempt to reduce unnecessary sick leave requests. For instance, for cases in which a medical condition 
requires a sick leave, other activities should be programmed to maintain a certain level of physical activity and self-esteem. We believe that if information regarding marital status, occupation status and maternal personality traits were collected and included in the obstetric history, identifying women who are at a high risk of developing PPD would be easier. This low-cost and relatively easy solution would assist in postpartum follow-up examinations of women with an increased susceptibility to PPD. Intervention studies to support this conclusion should be conducted.

\section{References}

Akincigil, A., Munch, S., \& Niemczyk, K. C. (2010). Predictors of maternal depression in the first year postpartum: Marital status and mediating role of relationship quality. Social Work in Health Care, 49(3), 227-244.

Akman, C., Uguz, F., \& Kaya, N. (2007). Postpartum-onset major depression is associated with personality disorders. Comprehensive Psychiatry, 48(4), 343-347.

Albacar, G., Sans, T., Martin-Santos, R., Garcia-Esteve, L., Guillamat, R., Sanjuan, J., et al. (2011). An association between plasma ferritin concentrations measured $48 \mathrm{~h}$ after delivery and postpartum depression. Journal of Affective Disorders, 131(1-3), 136-142.

Alfonsi, G., Conway, M., \& Pushkar, D. (2011). The lower subjective social status of neurotic individuals: Multiple pathways through occupational prestige, income, and illness. Journal of Personality, 79(3), 619-642.

Beck, C. T. (2001). Predictors of postpartum depression: An update. Nursing Research, 50(5), 275-285.

Bermejo, I., Kriston, L., Schneider, F., Gaebel, W., Hegerl, U., Berger, M., et al. (2010). Sick leave and depression - determining factors and clinical effect in outpatient care. Psychiatry Research, 180(2-3), 68-73.

Boyd, R. C., Mogul, M., Newman, D., \& Coyne, J. C. (2011). Screening and referral for postpartum depression among low-income women: A qualitative perspective from community health workers. Depression Research and Treatment, 2011, 320605.

Brummelte, S., \& Galea, L. A. (2010). Depression during pregnancy and postpartum: Contribution of stress and ovarian hormones. Progress in Neuro-Psychopharmacology $\mathcal{E}$ Biological Psychiatry, 34(5), 766-776.

Chen, C. H. (2001). Association of work status and mental well-being in new mothers. The Kaohsiung Journal of Medical Sciences, 17(11), 570-575.

Costas, J., Gratacos, M., Escaramis, G., Martin-Santos, R., de Diego, Y., Baca-Garcia, E., et al. (2010). Association study of 44 candidate genes with depressive and anxiety symptoms in post-partum women. Journal of Psychiatric Research, 44(11), 717-724.

Ekuklu, G., Tokuc, B., Eskiocak, M., Berberoglu, U., \& Saltik, A. (2004). Prevalence of postpartum depression in edirne, turkey, and related factors. The Journal of Reproductive Medicine, 49(11), 908-914.

Ersek, J. L., \& Brunner Huber, L. R. (2009). Physical activity prior to and during pregnancy and risk of postpartum depressive symptoms. Journal of Obstetric, Gynecologic, and Neonatal Nursing : JOGNN / NAACOG, 38(5), 556-566. 
Garcia-Esteve, L., Ascaso, C., Ojuel, J., \& Navarro, P. (2003). Validation of the edinburgh postnatal depression scale (EPDS) in spanish mothers. Journal of Affective Disorders, 75(1), 71-76.

Goyal, D., Gay, C., \& Lee, K. A. (2010). How much does low socioeconomic status increase the risk of prenatal and postpartum depressive symptoms in first-time mothers? Women's Health Issues: Official Publication of the Jacobs Institute of Women's Health, 20(2), 96-104.

Inandi, T., Elci, O. C., Ozturk, A., Egri, M., Polat, A., \& Sahin, T. K. (2002). Risk factors for depression in postnatal first year, in eastern turkey. International Journal of Epidemiology, 31(6), 1201-1207.

Jardri, R., Pelta, J., Maron, M., Thomas, P., Delion, P., Codaccioni, X., et al. (2006). Predictive validation study of the edinburgh postnatal depression scale in the first week after delivery and risk analysis for postnatal depression. Journal of Affective Disorders, 93(1-3), 169-176.

Jones, L., Scott, J., Cooper, C., Forty, L., Smith, K. G., Sham, P., et al. (2010). Cognitive style, personality and vulnerability to postnatal depression. The British Journal of Psychiatry: The Journal of Mental Science, 196(3), 200-205.

Josefsson, A., Angelsioo, L., Berg, G., Ekstrom, C. M., Gunnervik, C., Nordin, C., et al. (2002). Obstetric, somatic, and demographic risk factors for postpartum depressive symptoms. Obstetrics and Gynecology, 99(2), 223-228.

Kozinszky, Z., Dudas, R. B., Csatordai, S., Devosa, I., Toth, E., Szabo, D., et al. (2011). Social dynamics of postpartum depression: A population-based screening in southeastern hungary. Social Psychiatry and Psychiatric Epidemiology, 46(5), 413-423.

Lane, A., Keville, R., Morris, M., Kinsella, A., Turner, M., \& Barry, S. (1997). Postnatal depression and elation among mothers and their partners: Prevalence and predictors. The British Journal of Psychiatry : The Journal of Mental Science, 171, 550555.

Larsson, C., Sydsjo, A., Alexanderson, K., \& Sydsjo, G. (2006). Obstetricians' attitudes and opinions on sickness absence and benefits during pregnancy. Acta Obstetricia Et Gynecologica Scandinavica, 85(2), 165-170.

Leung, B. M., \& Kaplan, B. J. (2009). Perinatal depression: Prevalence, risks, and the nutrition link--a review of the literature. Journal of the American Dietetic Association, 109(9), 1566-1575.

Mahon, P. B., Payne, J. L., MacKinnon, D. F., Mondimore, F. M., Goes, F. S., Schweizer, B., et al. (2009). Genome-wide linkage and follow-up association study of postpartum mood symptoms. The American Journal of Psychiatry, 166(11), 1229-1237.

McGarry, J., Kim, H., Sheng, X., Egger, M., \& Baksh, L. (2009). Postpartum depression and help-seeking behavior. Journal of Midwifery \& Women's Health, 54(1), 50-56.

Miyake, Y., Tanaka, K., Sasaki, S., \& Hirota, Y. (2011). Employment, income, and education and risk of postpartum depression: The osaka maternal and child health study. Journal of Affective Disorders, 130(1-2), 133-137.

O'Hara, M. W. (2009). Postpartum depression: What we know. Journal of Clinical Psychology, 65(12), 1258-1269. 
Oppo, A., Mauri, M., Ramacciotti, D., Camilleri, V., Banti, S., Borri, C., et al. (2009). Risk factors for postpartum depression: The role of the postpartum depression predictors inventory-revised (PDPI-R). results from the perinatal depressionresearch \& screening unit (PNDReScU) study. Archives of Women's Mental Health, 12(4), 239-249.

Ortet G, M. M. (1997). Cuestionario revisado de personalidad Eysenk. Madrid: TEA Ediciones SA.

Pearlstein, T., Howard, M., Salisbury, A., \& Zlotnick, C. (2009). Postpartum depression. American Journal of Obstetrics and Gynecology, 200(4), 357-364.

Posmontier, B. (2008). Functional status outcomes in mothers with and without postpartum depression. Journal of Midwifery $\mathcal{E}$ Women's Health, 53(4), 310-318.

Rich-Edwards, J. W., Kleinman, K., Abrams, A., Harlow, B. L., McLaughlin, T. J., Joffe, H., et al. (2006). Sociodemographic predictors of antenatal and postpartum depressive symptoms among women in a medical group practice. Journal of Epidemiology and Community Health, 60(3), 221-227.

Roca, M., Martin-Santos, R., Saiz, J., Obiols, J., Serrano, M. J., Torrens, M., et al. (2007). Diagnostic interview for genetic studies (DIGS): Inter-rater and test-retest reliability and validity in a spanish population. European Psychiatry: The Journal of the Association of European Psychiatrists, 22(1), 44-48.

Rubertsson, C., Wickberg, B., Gustavsson, P., \& Radestad, I. (2005). Depressive symptoms in early pregnancy, two months and one year postpartum-prevalence and psychosocial risk factors in a national swedish sample. Archives of Women's Mental Health, 8(2), 97-104.

Sanjuan, J., Martin-Santos, R., Garcia-Esteve, L., Carot, J. M., Guillamat, R., Gutierrez-Zotes, A., et al. (2008). Mood changes after delivery: Role of the serotonin transporter gene. The British Journal of Psychiatry : The Journal of Mental Science, 193(5), 383-388.

Stankunas, M., Kalediene, R., Starkuviene, S., \& Kapustinskiene, V. (2006). Duration of unemployment and depression: A cross-sectional survey in lithuania. BMC Public Health, 6, 174.

Sydsjo, A., Sydsjo, G., \& Alexanderson, K. (2001). Influence of pregnancy-related diagnoses on sick-leave data in women aged 16-44. Journal of Women's Health $\mathcal{E}$ Gender-Based Medicine, 10(7), 707-714.

Sydsjo, G., \& Sydsjo, A. (2005). No association found between sickness absence and duration of pregnancy benefit. Scandinavian Journal of Primary Health Care, 23(3), 178-183.

Tannous, L., Gigante, L. P., Fuchs, S. C., \& Busnello, E. D. (2008). Postnatal depression in southern brazil: Prevalence and its demographic and socioeconomic determinants. BMC Psychiatry, 8, 1.

Treloar, S. A., Martin, N. G., Bucholz, K. K., Madden, P. A., \& Heath, A. C. (1999). Genetic influences on post-natal depressive symptoms: Findings from an australian twin sample. Psychological Medicine, 29(3), 645-654.

Warner, R., Appleby, L., Whitton, A., \& Faragher, B. (1996). Demographic and obstetric risk factors for postnatal psychiatric morbidity. The British Journal of Psychiatry : The Journal of Mental Science, 168(5), 607-611. 
Weiss, B. D., Sheehan, C. P., \& Gushwa, L. L. (2009). Is low literacy a risk factor for symptoms of depression in postpartum women? The Journal of Reproductive Medicine, 54(9), 563-568. 


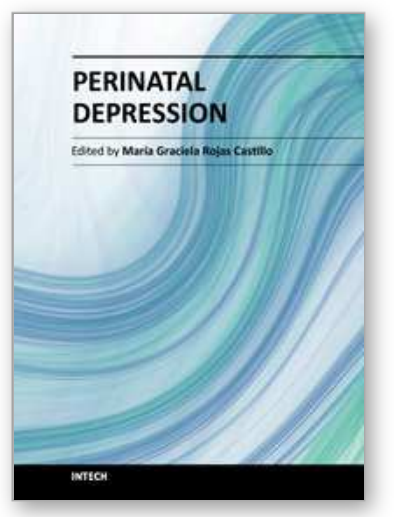

\author{
Perinatal Depression \\ Edited by Dr. María Graciela Rojas Castillo
}

ISBN 978-953-307-826-7

Hard cover, 190 pages

Publisher InTech

Published online 20, January, 2012

Published in print edition January, 2012

This book presents ten chapters that give us important information about epidemiological, biological, clinical and psychological aspects of common mental disorders during pregnancy and in the postnatal period. Some of the issues covered in this book are: detecting postnatal depression using different instruments at the right time, which is very important to avoid the negative effects on the children of depressed mothers; understanding the impact of anxiety and depression during pregnancy and in the postnatal period; biological issues of perinatal anxiety and depression; epidemiological information about perinatal mental health problems among minorities, like immigrant population and underserved rural women. Some information is also provided on postnatal depression in men, which is frequently overlooked.

\title{
How to reference
}

In order to correctly reference this scholarly work, feel free to copy and paste the following:

Elisabet Vilella, Glòria Albacar, Rocío Martín-Santos, Lluïsa García-Esteve, Roser Guillamat, Julio Sanjuan, Francesca Cañellas, Isolde Gornemann, Yolanda de Diego, Ana Gaviria and Alfonso Gutiérrez-Zotes (2012). Employment During Pregnancy Protects Against Postpartum Depression, Perinatal Depression, Dr. María Graciela Rojas Castillo (Ed.), ISBN: 978-953-307-826-7, InTech, Available from:

http://www.intechopen.com/books/perinatal-depression/employment-during-pregnancy-protects-againstpostpartum-depression

\section{INTECH}

open science | open minds

\author{
InTech Europe \\ University Campus STeP Ri \\ Slavka Krautzeka 83/A \\ 51000 Rijeka, Croatia \\ Phone: +385 (51) 770447 \\ Fax: +385 (51) 686166 \\ www.intechopen.com
}

\author{
InTech China \\ Unit 405, Office Block, Hotel Equatorial Shanghai \\ No.65, Yan An Road (West), Shanghai, 200040, China \\ 中国上海市延安西路65号上海国际贵都大饭店办公楼405单元 \\ Phone: +86-21-62489820 \\ Fax: $+86-21-62489821$
}


(C) 2012 The Author(s). Licensee IntechOpen. This is an open access article distributed under the terms of the Creative Commons Attribution 3.0 License, which permits unrestricted use, distribution, and reproduction in any medium, provided the original work is properly cited. 